\title{
Xanthine Oxidoreductase Reference Values in Platelet-Poor Plasma and Platelets in Healthy Volunteers
}

\author{
Elżbieta Cecerska-Heryć, Anna Jesionowska, Szupiluk Klaudyna, Siewierska Katarzyna, \\ Mączka Dominika, Pawlak Dominika, Urbańska Marta, and Barbara Dołęgowska
}

\author{
Department of Laboratory Diagnostics and Molecular Medicine, Pomeranian Medical University of Szczecin, \\ Powstancow Wielkopolskich 72, 70-111 Szczecin, Poland
}

Correspondence should be addressed to Elżbieta Cecerska-Heryć; cecerskaela@wp.pl

Received 5 November 2014; Revised 18 December 2014; Accepted 24 December 2014

Academic Editor: Angel Catalá

Copyright @ 2015 Elżbieta Cecerska-Heryć et al. This is an open access article distributed under the Creative Commons Attribution License, which permits unrestricted use, distribution, and reproduction in any medium, provided the original work is properly cited.

\begin{abstract}
Introduction. Xanthine oxidoreductase (XOR) is an enzyme belonging to the class of hydroxylases. XOR is stated, inter alia, in the kidneys, liver, and small intestine as well as in leukocytes and platelets and endothelial cells of capillaries. Its main role is to participate in the conversion of hypoxanthine to xanthine and the uric acid. It occurs in two isoforms: dehydrogenase (XD) and oxidase (XO), which is considered one of the sources of reactive oxygen species. Aim of the Study. Determination of reference values of xanthine oxidoreductase activity in PPP and platelets. Materials and Methods. Study group consisted of 70 healthy volunteers. The isoform activities of xanthine oxidoreductase were determined by kinetic spectrophotometry. Results. A statistically significant difference between the activity of the XOR in PPP and platelets $(P<0.001)$. The highest activity of XO was found in both PPP and blood platelets. Significant differences between the activity of the various isoforms in PPP $(P=0.0032)$ and platelets $(P<0.001)$ were also found. Conclusions. The healthy volunteers showed the highest activity XO (prooxidant) and the lowest XD (antioxidant), which indicates a slight oxidative stress and confirmed physiological effects of XOR.
\end{abstract}

\section{Introduction}

Xanthine oxidoreductase (XOR) is a molybdate hydroxylase, which is to catalyze the oxidation of hypoxanthine to xanthine and xanthine to uric acid. It comes in two mutually converting alternative isoforms: xanthine dehydrogenase (XD), expressed in vivo as well as in healthy tissue of the parent, and xanthine oxidase $(\mathrm{XO})$, generated by the posttranslational modification of the $\mathrm{XD}$ or by oxidation of cysteine residues and also limited proteolysis, which plays a dominant role in cells and tissues during trauma [1-3]. Both isoforms act in opposition to each other. XD feedstock for the oxidation of the oxidized form $\mathrm{NAD}^{+}$also has a preference for the $\mathrm{NAD}^{+}$as a cosubstrate, also has the ability to react with $\mathrm{O}_{2}$ [4], and also catalyzes a reaction in which uric acid (UA) is synthesized. It has demonstrated a protective effect in the body, to trap the reactive oxygen species (ROS), and acts as an antioxidant [5].

On the other hand, $\mathrm{XO}$ is unable to bind $\mathrm{NAD}^{+}$, and $\mathrm{O}_{2}$ is used in the reaction associated with increased synthesis of ROS and RNS (reactive forms of nitrogen), which is an important relay inflammatory response through the activation of the complement system or modulation of endothelial P-selectin expression on the cell surface [6]. It is xanthine oxidase that is considered to be the main source of reactive oxygen species in a variety of clinical settings as well as under conditions of hypoxia and reperfusion and organ failure [1].

Xanthine oxidoreductase itself can act in two ways: in the presence of $\mathrm{NAD}^{+}$as dehydrogenase and molecular oxygen as an oxidase. The ability to rapidly convert XOR of antioxidant to the oxidant, the various kinds of tissue damage, is an essential element for rapid innate immune response, a preferred example in bacterial or fungal infection [7].

Xanthine dehydrogenase, reactive oxygen intermediate form called (XDO), and its presence were assumed since the 70 s of the last century. It reacts with both $\mathrm{NAD}^{+}$and $\mathrm{O}_{2}$, with the proviso that it retains greater affinity for $\mathrm{NAD}^{+}$. The activity of both XD and XDO is regulated by the $\left[\mathrm{NAD}^{+}\right] /\left[\mathrm{NADH}+\mathrm{H}^{+}\right][8]$. The isolation of the intermediate isoform is irrelevant molecular, but the indication of its 
activity, allows to follow the process of transforming the dehydrogenase to oxidase isoforms [9].

The literature reports cannot be found, on the activity of the various isoforms of xanthine oxidoreductase plateletpoor plasma (PPP) and platelet-rich plasma (PRP) in healthy controls. It has been shown, however, that the activity of the $\mathrm{XOR}$ in the serum of healthy individuals is very low, which corresponds to the production of less than $4 \mathrm{O}_{2} / \mathrm{mL}$ plasma $\mathrm{nmol} / \mathrm{min}$ (calculated as the reduction of ferricytochrome C ROS). However, the growth is a characteristic of various pathological conditions such as viral hepatitis, autoimmune rheumatic diseases, chronic kidney disease, type 2 diabetes, and schizophrenia $[10,11]$. Important physiological XOR and forecasting in the case of many diseases such as cancer require knowledge of xanthine oxidoreductase reference standards in PPP and in platelets, which is also the aim of this work.

\section{Materials and Methods}

The material was collected in the morning from 70 healthy volunteers fasted, among whom were 48 women and 29 men. After downloading the material, volunteers were asked to fill out a survey on the general information about the patient and his health condition. In addition to marking the XOR and its isoforms, blood counts and biochemical tests were also performed, in all volunteers. Patients were divided into two groups above and below 30 years of age in order to perform further analyses (detailed information about the volunteers: Table 1).

The determinations were made in PPP and in platelet lysates (Table 2 ). The plasma was thawed at room temperature and then centrifuged $\left(10 \mathrm{~min}, 4^{\circ} \mathrm{C}\right.$, and $\left.3824 \mathrm{~g}\right)$. The plates were thawed at room temperature and then centrifuged $\left(10 \mathrm{~min}, 4^{\circ} \mathrm{C}\right.$, and $\left.3824 \mathrm{~g}\right)$ to give a clear lysate $[12,13]$.

2.1. Xanthine Oxidoreductase Activity Determination of Plasma and Platelets. Reagents Trizma base; $\mathrm{NAD}^{+}$; xanthine; $\mathrm{CuSO}_{4} * 5 \mathrm{H}_{2} \mathrm{O}$ were purchased from Sigma Aldrich (Poznan, Poland). Determinations were performed using a UV/VIS Lambda 40P (Perkin Elmer). Extinction changes were recorded for 5 minutes at $30^{\circ} \mathrm{C}$. The enzymatic activity was measured as formation of uric acid and NADH (increases in $\mathrm{A}_{340}$ and $\mathrm{A}_{302}$ ) and expressed in $\mathrm{mU} / \mathrm{mL}$ (milliunits per milliliter). The enzymatic activity was calculated taking into account the initial rates of reaction. Uric acid formation was measured at $302 \mathrm{~nm}$ (isoforms XDO and XO) because its absorbance is still high there, whereas changes in $\mathrm{NAD}^{+}$ concentration do not contribute. During the calculation of isoforms activity of xanthine oxidoreductase included molar extinction coefficients: $\mathrm{NADH}+\mathrm{H}^{+} \varepsilon 340=6.22$ $\times 103 \mathrm{~L} \mathrm{~mol}^{-1} \times \mathrm{cm}^{-1} ; \mathrm{NADH}+\mathrm{H}^{+} \varepsilon 302=2.30 \times 10^{3} \times$ $\mathrm{mol}^{-1} \mathrm{~cm}^{-1}[8,9]$.

2.2. Xanthine Oxidoreductase Activity Determination of $P P P$. Isoform dehydrogenase $(\mathrm{XDH})$ was determined by measuring the increase in the extinction of the test sample (500 mM NAD ${ }^{+}, 50 \mathrm{mM}$ buffer Tris/HCl: $\mathrm{pH} 8.0$, and $100 \mathrm{mM}$ xanthine; PPP) at a wavelength of $340 \mathrm{~nm}$ against the
TABle 1: (a) Parameters describing the healthy volunteers. (b) Parameters describing the healthy volunteers.

(a)

\begin{tabular}{lcccc}
\hline $\begin{array}{l}\text { Parameters } \\
\text { characterizing } \\
\text { healthy volunteers }\end{array}$ & Female & Male & $P$ value \\
\hline $\begin{array}{l}\text { Number of healthy } \\
\text { volunteers }\end{array}$ & 70 & 48 & 29 & NS \\
Age $>30$ years & 20 & 14 & 6 & $<0.001$ \\
Age $<30$ years & 49 & 34 & 15 & $<0.001$ \\
Smoking & 10 & 8 & 2 & NS \\
\hline
\end{tabular}

NS: no statistical significance.

(b)

\begin{tabular}{lc}
\hline \multicolumn{2}{c}{ Parameters characterizing healthy volunteers } \\
\hline Heart diseases & 2 \\
Hypertension & 6 \\
Diabetes & 1 \\
Kidney disease & 6 \\
Vascular disease & 6 \\
Related allergological diseases & 19 \\
\hline
\end{tabular}

NS: no statistical significance.

blank (500 mM NAD ${ }^{+}$, buffer $50 \mathrm{mM}$ Tris/HCl: $\mathrm{pH} 8.0$, and $100 \mathrm{mM}$ xanthine).

Intermediate isoform (XDO) was determined by measuring the increase in the extinction test sample $\left(500 \mathrm{mM} \mathrm{NAD}^{+}\right.$, $50 \mathrm{mM}$ Tris buffer/HCl: $\mathrm{pH}$ 8.0, and $100 \mathrm{mM}$ xanthine; PPP) at a wavelength of $302 \mathrm{~nm}$, against the blank $\left(500 \mathrm{mM} \mathrm{NAD}^{+}\right.$, buffer 50 mM Tris/HCl: $\mathrm{pH} 8.0$, and $100 \mathrm{mM}$ xanthine).

Isoform oxidase (XO) was determined by recording an increase in the extinction test sample $\left(500 \mathrm{mM} \mathrm{NAD}^{+}\right.$, $50 \mathrm{mM}$ Tris buffer/HCl: $\mathrm{pH}$ 8.0, and $100 \mathrm{mM}$ xanthine; PPP) at a wavelength of $302 \mathrm{~nm}$ against the blank (500 mM NAD, buffer $50 \mathrm{mM}$ Tris/HCl: $\mathrm{pH} 8.0$, and $100 \mathrm{mM}$ xanthine) $[8,9]$.

2.3. Determination of Xanthine Oxidoreductase Activity Platelets. Isoform dehydrogenase $(\mathrm{XDH})$ was determined by measuring the increase in the extinction of the test sample $\left(250 \mathrm{mM} \mathrm{NAD}{ }^{+}, 50 \mathrm{mM}\right.$ buffer Tris/HCl: $\mathrm{pH} 8.0$, $50 \mathrm{mM}$ xanthine, and $5 \mathrm{mM} \mathrm{CuSO}_{4}$; platelet lysate) at a wavelength of $340 \mathrm{~nm}$ against the blank $\left(250 \mathrm{mM} \mathrm{NAD}^{+}\right.$, $50 \mathrm{mM}$ buffer Tris/HCl: $\mathrm{pH}$ 8.0, $50 \mathrm{mM}$ xanthine, and $5 \mathrm{mM}$ $\mathrm{CuSO}_{4}$ ) (Figures 1 and 2).

Intermediate isoform (XDO) was determined by measuring the increase in the extinction of the test sample $\left(250 \mathrm{mM} \mathrm{NAD}{ }^{+}, 50 \mathrm{mM}\right.$ buffer Tris/HCl: $\mathrm{pH}$ 8.0, $50 \mathrm{mM}$ xanthine, and $5 \mathrm{mM} \mathrm{CuSO}_{4}$; platelet lysate) at a wavelength of $302 \mathrm{~nm}$, compared to the blank ( $250 \mathrm{mM} \mathrm{NAD}^{+}, 50 \mathrm{mM}$ buffer Tris/ $\mathrm{HCl}$ : $\mathrm{pH}$ 8.0, $50 \mathrm{mM}$ xanthine, and $5 \mathrm{mM} \mathrm{CuSO}_{4}$ ).

Isoform oxidase (XO) was determined by recording an increase in the extinction test sample $\left(500 \mathrm{mM} \mathrm{NAD}^{+}\right.$, $50 \mathrm{mM}$ Tris buffer/HCl: $\mathrm{pH}$ 8.0, and $100 \mathrm{mM}$ xanthine; PPP) at a wavelength of $302 \mathrm{~nm}$ against the blank $\left(250 \mathrm{mM} \mathrm{NAD}^{+}\right.$, buffer $50 \mathrm{mM}$ Tris/HCl: $\mathrm{pH} 8.0,50 \mathrm{mM}$ xanthine, and $5 \mathrm{mM}$ $\left.\mathrm{CuSO}_{4}\right)[8,9]$. 
TABle 2: Xanthine oxidoreductase activity in PPP and platelets, in the individual isoforms (mean \pm SD).

\begin{tabular}{lcc}
\hline Variable activity $[\mathrm{mU} / \mathrm{mL}]$ & Mean \pm SD & Minimum; maximum \\
\hline XDH PPP & $38.7 \pm 16.2$ & $11.8 ; 99.1$ \\
XDH platelets & $6.9 \pm 3.6$ & $1.6 ; 18.03$ \\
XDO PPP & $39.1 \pm 19.5$ & $1.6 ; 116.2$ \\
XDO platelets & $11.6 \pm 5.1$ & $1.5 ; 27.3$ \\
XO PPP & $49.6 \pm 18.9$ & $10.7 ; 96.6$ \\
XO platelets & $12.2 \pm 5.37$ & $0.65 ; 25.2$ \\
Xanthine oxidoreductase activity in PPP & $42.5 \pm 18.8$ & $1.57 ; 116.2$ \\
Xanthine oxidoreductase activity in platelets & $10.2 \pm 5.3$ & $0.65 ; 27.3$ \\
\hline
\end{tabular}

SD: standard deviation.

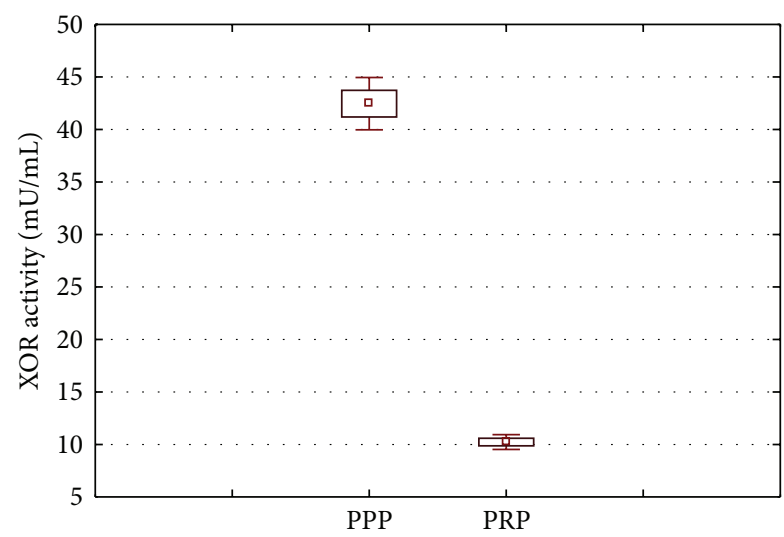

FIGURE 1: Comparison of activity in PPP XOR and platelets $(P<$ $0.001)$. Whiskers show the value of the lower and upper quartile.

2.4. Statistical Analysis. The results were statistically analyzed. The assessment of normality of distributions was performed by Shapiro-Wilk test. To assess the differences between the studied parameters, $t$-tests for related and unrelated variables and one-way ANOVA were used. Analysis of variance was performed using $F$-test (for the two series of analyses of variance) and Levene's test (for homogeneity of variance multiple series). The assumptions required for the application of analysis of variance (normality of distribution and homoscedasticity) are not violated in a way that could disrupt the reliability of statistics $F$. Chi-square test was used to analyze qualitative data.

Statistical study of the results was performed using the statistical program STATISTICA GB 10 (StatSoft). The level of statistical significance was taken as $P<0.05$.

\section{Results}

There is a statistically significant difference $(P<0.001)$ between the activity of xanthine oxidoreductase PPP in plasma and its activity in platelets (PRP). Higher activity in all isoforms oxidoreductase PPP compared to its activity in platelets was also demonstrated. Highest activity of XO and $\mathrm{XDH}$ in both serum and the PPP and PRP isoforms was observed best. The differences in the activity of the individual
TABLE 3: XOR reference values and its isoforms in PPP and platelets, in healthy volunteers.

\begin{tabular}{lc}
\hline $\begin{array}{l}\text { Reference values and its isoforms XOR PPP and platelets } \\
\text { in healthy control }\end{array}$ \\
\hline XOR PPP & $10.93-23.58$ \\
XOR platelets & $3.28-23.58$ \\
XD PPP & $14.05-89.86$ \\
XD platelets & $2.46-17.22$ \\
XDO PPP & $5.89-88.28$ \\
XDO platelets & $2.75-24.98$ \\
XO PPP & $19.06-86.90$ \\
XO platelets & $3.55-24.87$ \\
\hline
\end{tabular}

isoforms are statistically significant and are, respectively, PPP $P=0.0032$ and the platelet $P<0.001$.

3.1. Xanthine Oxidoreductase Activity of Patient Age and Gender. There was no effect of gender on patient activity of xanthine oxidoreductase. There was no effect of age on the enzyme activity, while in the case of oxidoreductase activity in PPP close correlation was statistically significant $(P=0.055)$, wherein the substantially higher activity of the oxidoreductase occurred among people over 30 years of age (Figure 4).

3.2. Reference Value Calculation Xanthine Oxidoreductase. XOR reference values and its isoforms were determined in the range of 2.5-97.5 percentile obtained by the spectrophotometric determinations of enzyme activity (Table 3 ).

\section{Discussion}

Xanthine oxidoreductase activity in human and animal tissues has been quite extensively studied by many researchers. On the basis of these results, it is determined that the highest activity of the XOR is present in the liver and intestine, and ambiguous results were obtained with serum, skeletal muscle, brain, and heart. Such studies were also carried out for various kinds of diseases [14]. For example, Aliciguzel et al. showed that there was no significant difference in the activity of $\mathrm{XDH}$ and $\mathrm{XO}$ in the liver of rats with early and late diabetic 


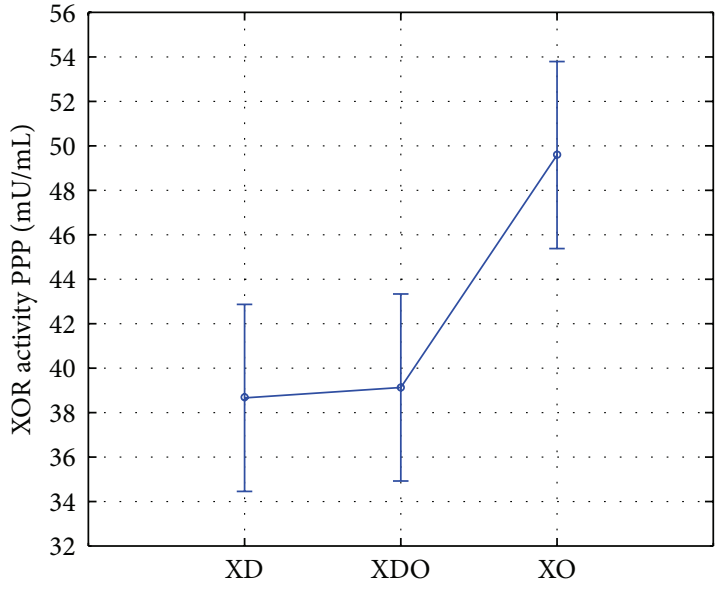

(a)

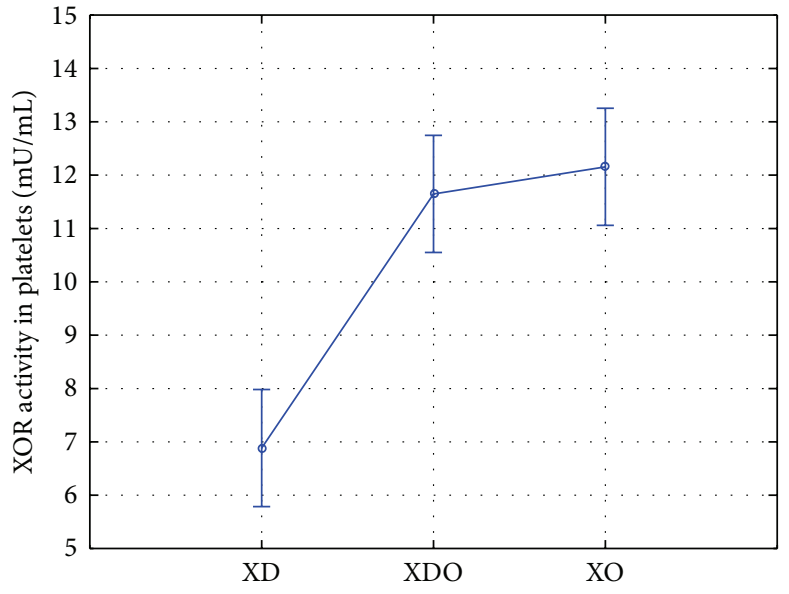

(b)

FIgURE 2: ANOVA analysis of the relationship in the activity of the various isoforms in xanthine oxidoreductase PPP (a) $(P=0,0032)$ and platelets (b) $(P<0,001)$ (mean $\pm 95 \% \mathrm{CI})$. XDH: dehydrogenase isoform; XDO: isoform dehydrogenase-oxidase (indirect); XO: oxidase isoform.

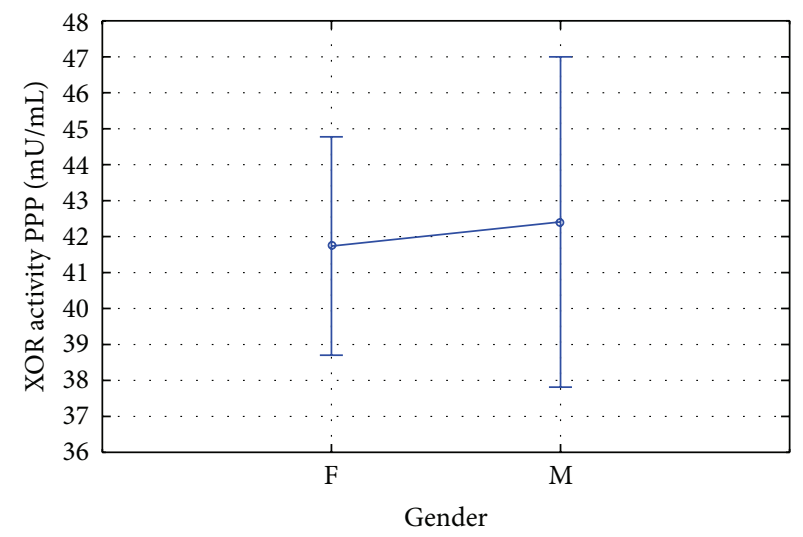

(a)

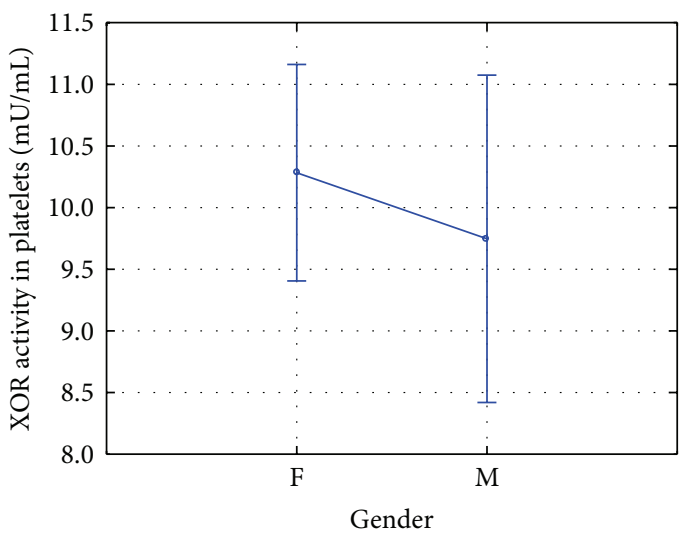

(b)

FIGURE 3: Based on the ANOVA analysis of healthy volunteers between sex and xanthine oxidoreductase activity in PPP (a) and platelets (b) (mean $\pm 95 \% \mathrm{CI}$ ). The activity of xanthine oxidoreductase in the PPP according to gender $(P=0.811)$; xanthine oxidoreductase activity in platelets according to gender $(P=0.507)$.

group versus control. Compared to the control there was no significant difference in the activity of XO in the heart, kidney, and brain. However, the $\mathrm{XDH}$ activity in these tissues was significantly higher in diabetic rats than in late diabetic rats with early diabetic group or control [15].

In the literature, it is hard to find, in turn, information on the activity of XOR and its isoforms in platelet-poor plasma and platelets in healthy volunteers. Shamma et al. showed that the activity of the XOR in the serum of individuals not suffering from any disease is very low, which corresponds to the production of less than $4 \mathrm{O}_{2} / \mathrm{mL}$ plasma $\mathrm{nmol} / \mathrm{min}$ (calculated as the reduction of ferricytochrome C ROS). However, the growth is a characteristic of various pathological conditions such as viral hepatitis, autoimmune rheumatic diseases, chronic kidney disease, type 2 diabetes, and schizophrenia [11].
Other pieces of information on the activity in healthy individuals XOR in the material used in the above study were not found. Quite often is undertaken on the activity of the enzyme in the plasma of patients suffering from, for various kinds of diseases.

In this study, a higher activity of all isoforms XOR in PPP compared to platelets is showed. It was also a statistically significant difference in the activity of the enzyme in PPP and platelets, wherein the isoform $\mathrm{XO}$ showed the highest activity and XD the lowest one (Figure 3). However, in the case of the intermediate isoform higher activity is found in platelets more than in plasma, which indicates a more rapid conversion of the intermediate isoform XD. According to Dolegowska et al., XOR activity and its isoforms were tested in plasma in patients after renal transplantation divided into three groups: EGF: early, SGF: slow, DGF: delayed graft 


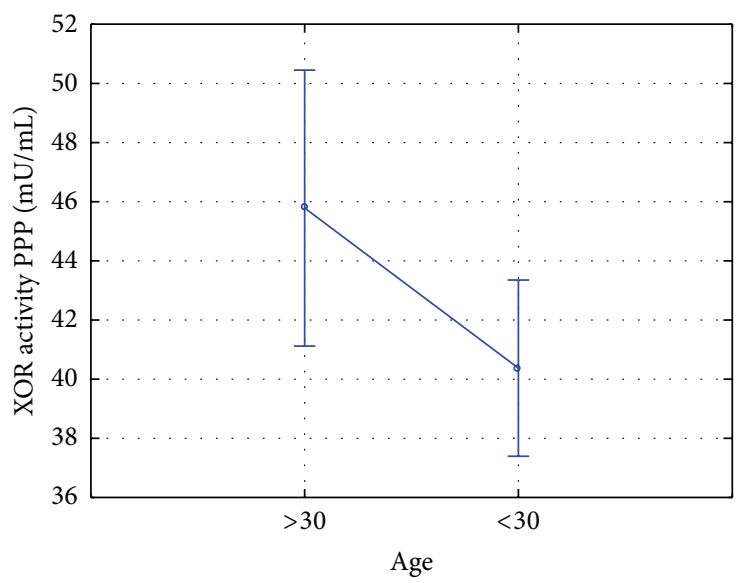

(a)

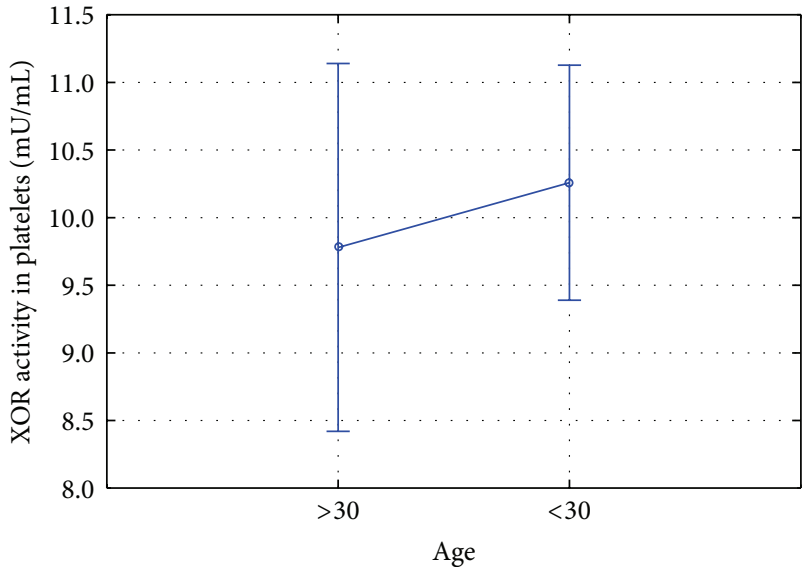

(b)

FIGURE 4: ANOVA analysis of the effects of age on healthy volunteers xanthine oxidoreductase activity in PPP (mean $\pm 95 \%$ CI). The activity of xanthine oxidoreductase in PPP in different age groups $(P=0.055)$; xanthine oxidoreductase activity in platelets in the different age groups $(P=0.559)$.

function. XO showed increased activity and XOR in all groups at 1 and 5 minutes after transplantation. XD activity increased in the groups of SGF and DGF also at 1 and 5 minutes. The highest activity was found in the isoform XD (having an antioxidant effect) and the lowest activity was found in isoform XO (having oxidative effects). This may mean that, in severe conditions of oxidative stress, such as organ transplant, comes to increased activity of the enzyme, leveling oxidative stress. This explains the highest activity $\mathrm{XO}$ isoforms in normal individuals not exposed to oxidative stress [3]. Kim et al., in turn, demonstrated that patients suffering from lung cancer survival are associated with the activity of XOR. Survival in patients with a higher activity of oxidoreductase is longer than that in patients with a lower activity of the enzyme [16]. Linder et al. achieved similar results in the case of serous ovarian cancer. They showed that a decreased XOR activity is associated with a worse prognosis of patients suffering from this disease, especially those with unfavorable prognostic profile [17].

Boban et al. studied the activity of the XOR and XO and $\mathrm{XDH}$ in patients with spontaneous hypertension and patients on dialysis. This study has shown that the total XOR activity was higher in the patients suffering from spontaneous hypertension, as compared to patients on dialysis. Also in this group the highest activity of $\mathrm{XDH}$ is showed, in relation to the control or dialysis.

On the other hand, the activity of $\mathrm{XO}$, which mainly contributes to the production of ROS, was the highest in the dialysis patients [18]. However, in another study, Linder et al. showed a lower XOR activity in the $62 \%$ of colon cancer tissues and the enzyme activity detectable in $22 \%$ as compared to healthy tissue. Also the degree of differentiation of tumor cells has an effect on the activity of XOR, which is significantly higher in cells having a large degree of variation. This means that the activity of the XOR is associated with the degree of differentiation of tumor and its advancement in the case of colon cancer and can be a prognostic factor [19].

In our study, there was no correlation between the activity of XOR and its isoforms and the age of subjects. However, XOR activity in the case of platelet-poor plasma result was close to statistical significance. This means that in order to be able to clearly put such a request it is necessary to increase the test group. No association was found between the activity of XOR and gender of healthy subjects. Decker and Levinson XOR activity assays by RIA showed a higher activity of the enzyme in male rats [20]. Results achieved by us in relation to the analysis of other authors confirm the physiological significance of xanthine oxidoreductase and demonstrate the utmost importance and the need for this type of research in the context of the prognostic significance of XOR in the case of many types of chronic diseases such as kidney disease or tumors of various types.

\section{Conclusions}

The healthy volunteers showed the highest activity isoform $\mathrm{XO}$ (prooxidant) and the lowest isoforms XD (antioxidant), which indicates a slight oxidative stress in people tested and confirmed physiological effects of XOR. There were significant differences in the activity of XOR and its isoforms in PPP and platelets. There was no correlation between the activity of XOR and the age and gender of healthy volunteers.

\section{Disclosure}

The paper has been read and approved for submission by all qualified authors.

\section{Conflict of Interests}

The authors declare no competing financial interests. 


\section{Acknowledgments}

The paper was funded by NCN no. 2011/01/B/NZ5/04235 (2011-2014). Grant title is "The potential immunomodulatory [sic] as a result of changes in bioactive lipid metabolism in patients with chronic kidney disease treated conservatively, peritoneal dialysis or hemodialysis."

\section{References}

[1] K. Okamoto, K. Matsumoto, R. Hille, B. T. Eger, E. F. Pai, and T. Nishino, "The crystal structure of xanthine oxidoreductase during catalysis: Implications for reaction mechanism and enzyme inhibition," Proceedings of the National Academy of Sciences of the United States of America, vol. 101, no. 21, pp. 79317936, 2004.

[2] A. Meneshian and G. B. Bulkley, "The physiology of endothelial xanthine oxidase: from urate catabolism to reperfusion injury to inflammatory signal transduction," Microcirculation, vol. 9, no. 3, pp. 161-175, 2002.

[3] B. Dolegowska, W. Blogowski, and L. Domanski, "Clinical evidence of the association between serum perioperative changes in xanthine metabolizing enzymes activity and early posttransplant kidney allograft function," Journal of the American College of Surgeons, vol. 211, no. 5, pp. 587-595, 2010.

[4] R. Hille and T. Nishino, "Flavoprotein structure and mechanism. 4. Xanthine oxidase and xanthine dehydrogenase," The FASEB Journal, vol. 9, no. 11, pp. 995-1003, 1995.

[5] B. F. Becker, "Towards the physiological function of uric acid," Free Radical Biology \& Medicine, vol. 14, no. 6, pp. 615-631, 1993.

[6] M. Takano, A. Meneshian, E. Sheikh et al., "Rapid upregulation of endothelial P-selectin expression via reactive oxygen species generation," American Journal of Physiology: Heart and Circulatory Physiology, vol. 283, no. 5, pp. H2054-H2061, 2002.

[7] C. Vorbach, R. Harrison, and M. R. Capecchi, "Xanthine oxidoreductase is central to the evolution and function of the innate immune system," Trends in Immunology, vol. 24, no. 9, pp. 512-517, 2003.

[8] Z. W. Kaminski and M. M. Jezewska, "Intermediate dehydrogenase-oxidase form of xanthine oxidoreductase in rat liver," Biochemical Journal, vol. 181, no. 1, pp. 177-182, 1979.

[9] B. Dolegowska, Predictive Factors of Delayed Kidney Graft Function-Analysis of Balance Prooxidant-Antioxidant and Arachidonic Acid Metabolism in Platelets and Plasma during IschemiaReperfusion, Pomeranian Medical University, Szczecin, Poland, 2009.

[10] M. G. Battelli, A. Bolognesi, and L. Polito, "Pathophysiology of circulating xanthine oxidoreductase: new emerging roles for a multi-tasking enzyme," Biochimica et Biophysica Acta, vol. 1842, no. 9, pp. 1502-1517, 2014.

[11] M. H. Shammaa, S. Nasrallah, T. Chaglassian, A. K. Kachadurian, and U. A. Al Khalidi, "Serum xanthine oxidase: a sensitive test of acute liver injury," Gastroenterology, vol. 48, no. 2, pp. 226-230, 1965.

[12] E. Rodrigo, G. Fernández-Fresnedo, J. C. Ruiz et al., "Similar impact of slow and delayed graft function on renal allograft outcome and function," Transplantation Proceedings, vol. 37, no. 3, pp. 1431-1432, 2005.

[13] N. R. Pandey, G. Kaur, M. Chandra, G. G. Sanwal, and M. K. Misra, "Enzymatic oxidant and antioxidants of human blood platelets in unstable angina and myocardial infarction,"
International Journal of Cardiology, vol. 76, no. 1, pp. 33-38, 2000.

[14] C. A. Pritsos, "Cellular distribution, metabolism and regulation of the xanthine oxidoreductase enzyme system," ChemicoBiological Interactions, vol. 129, no. 1-2, pp. 195-208, 2000.

[15] Y. Aliciguzel, I. Ozen, M. Aslan, and U. Karayalcin, "Activities of xanthine oxidoreductose and antioxidant enzymes in different tissues of diabetic rats," Journal of Laboratory and Clinical Medicine, vol. 142, no. 3, pp. 172-177, 2003.

[16] A. W. Kim, M. Batus, R. Myint et al., "Prognostic value of xanthine oxidoreductase expression in patients with non-small cell lung cancer," Lung Cancer, vol. 71, no. 2, pp. 186-190, 2011.

[17] N. Linder, R. Bützow, H. Lassus, M. Lundin, and J. Lundin, "Decreased xanthine oxidoreductase (XOR) is associated with a worse prognosis in patients with serous ovarian carcinoma," Gynecologic Oncology, vol. 124, no. 2, pp. 311-318, 2012.

[18] M. Boban, G. Kocic, S. Radenkovic et al., "Circulating purine compounds, uric acid, and xanthine oxidase/dehydrogenase relationship in essential hypertension and end stage renal disease," Renal Failure, vol. 36, no. 4, pp. 613-618, 2014.

[19] N. Linder, E. Martelin, M. Lundin et al., "Xanthine oxidoreductase-clinical significance in colorectal cancer and in vitro expression of the protein in human colon cancer cells," European Journal of Cancer, vol. 45, no. 4, pp. 648-655, 2009.

[20] D. E. Decker and D. J. Levinson, "Quantitation of rat liver xanthine oxidase by radioimmunoassay. A mechanism for sexspecific differences," Arthritis and Rheumatism, vol. 25, no. 3, pp. 326-332, 1982. 


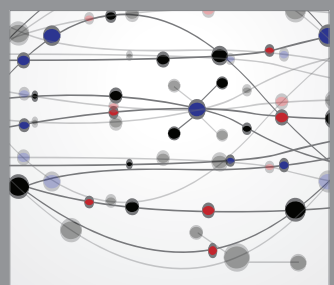

The Scientific World Journal
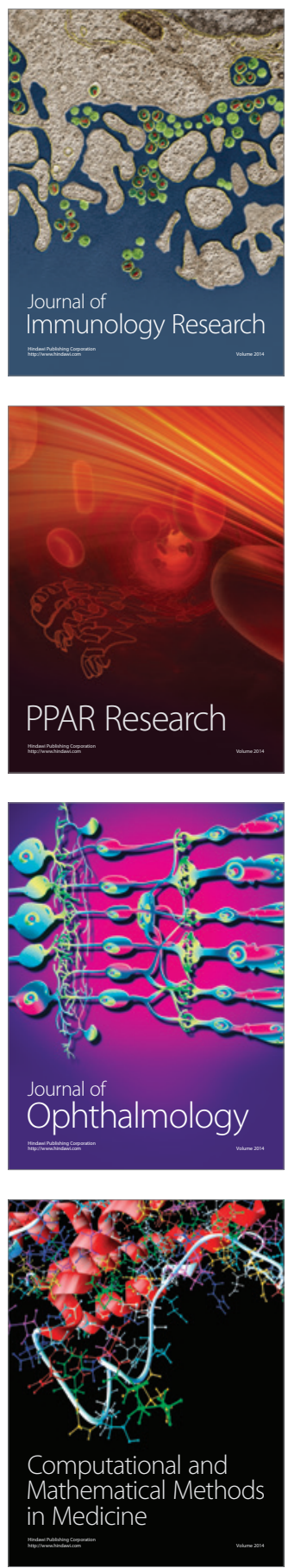

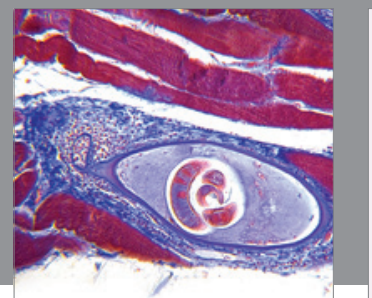

Gastroenterology

Research and Practice
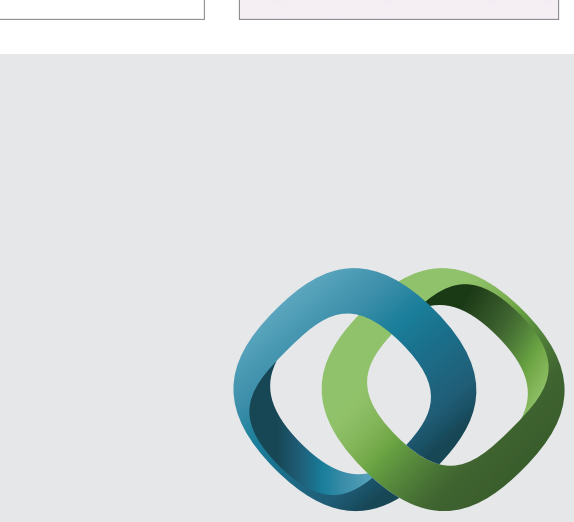

\section{Hindawi}

Submit your manuscripts at

http://www.hindawi.com
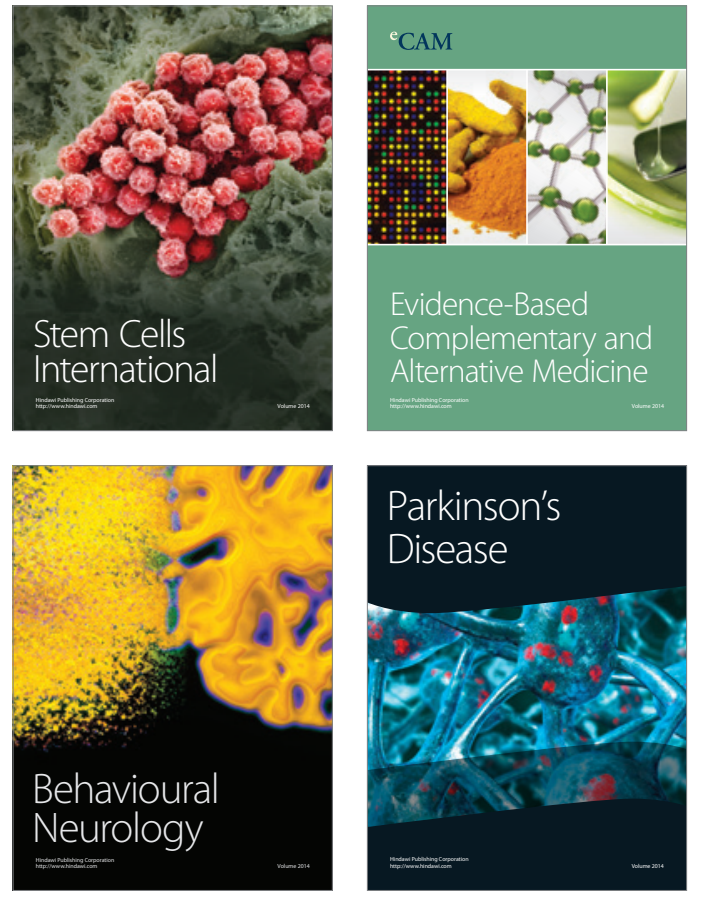
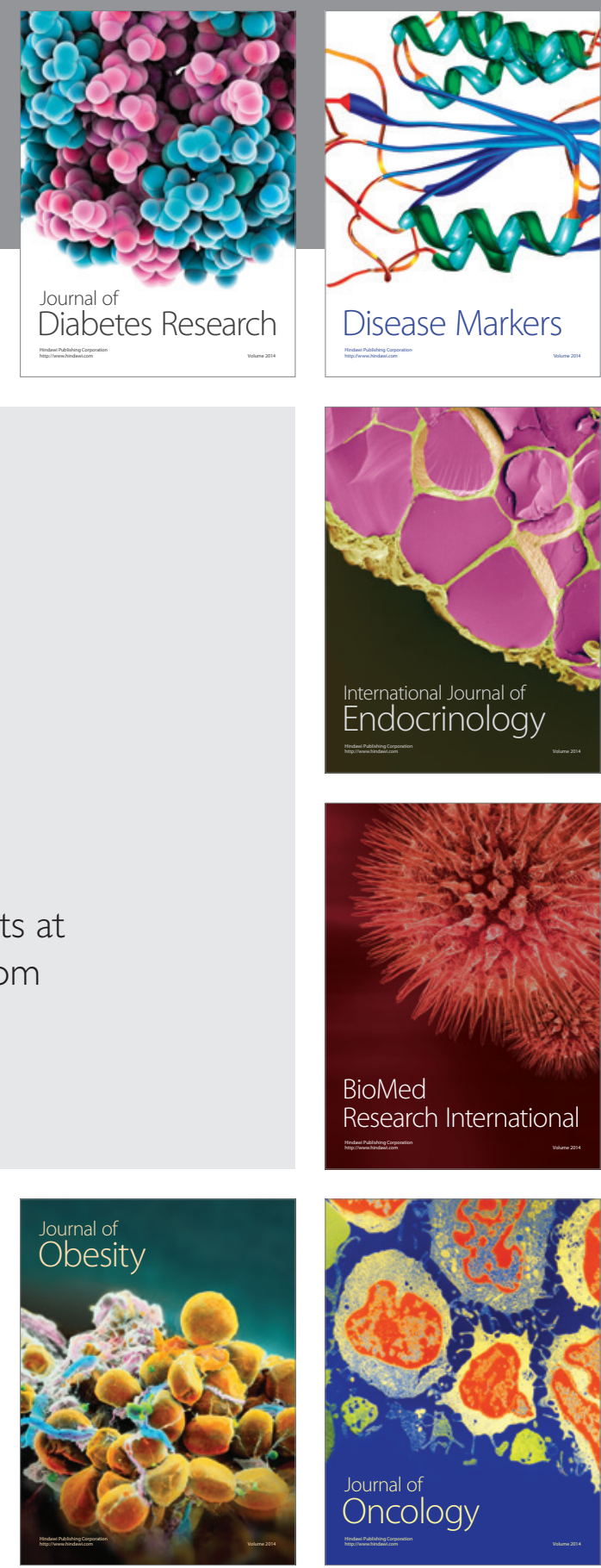

Disease Markers
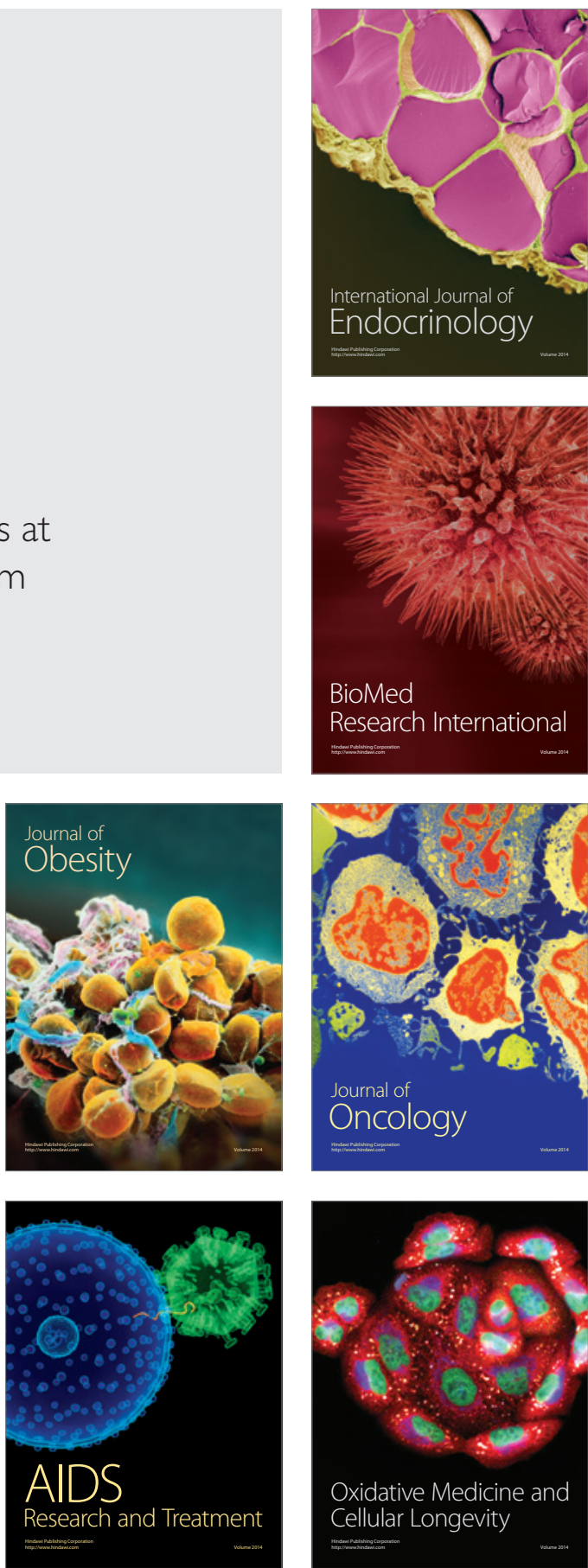